\title{
Children's Reactions to Divorce of Parents
}

\author{
Olaniyi Bojuwoye ${ }^{*}, 1$ and Orok Akpan ${ }^{2}$ \\ ${ }^{1}$ University of the Western Cape, Cape Town, South Africa \\ ${ }^{2}$ University of Kwazulu Natal, Durban, South Africa
}

\begin{abstract}
With divorce rate on the ascendancy, worldwide, increasing number of vulnerable children are growing up in "broken homes". Although divorce affect all children not all children react to it the same way. To some children, parental divorce is a personal tragedy, for other children, it is an escape from stressful lifestyle of family conflicts. Each child's personal factors and associated family dynamics determine how children react to parental divorce. The current study aimed at achieving two purposes - to ascertain various reactions of participants to parents' divorce, and to identify factors (personal, familial or environmental) which played significant influences on participants' reactions.

Participants comprised fifteen children (9 girls and 6 boys, with a mean age of 14.4 years) of a primary school in a suburb of Durban, South Africa. They were selected purposively although participation in the study was voluntary, parents had to consent to children's participation. Data collection was by face-to-face individual interview. Analysis of interview transcripts revealed varying patterns of reactions to parental divorce. Emotional and behavioural reactions commonly reported by participants include shock, disbelief, sadness, anger, confusion, loss, betrayal, rejection, abandonment and humiliation. Age, gender and varying family circumstances were found to have influenced participants' reactions to parents' divorce.
\end{abstract}

Keywords: Parental divorce, children's reactions, family dynamics, emotional and behavioural reactions, non-custodial parent, financial status, remarriage.

\section{INTRODUCTION AND BACKGROUND}

Although divorce is a major loss to children, however, not all children react the same way to their parents' divorce (Wade \& Tavris, 1993) [1]. Each child's reaction depends on how she/he perceives it (Clandos \& Kemp, 2007) [2] or the different personal or familial circumstances before or after the divorce (Clandos \& Kemp (2007) [2]; Hetherington (1989) [3]; Amato (1994) [4]). While some children react with anger, fear or tremendous grief, others are happy or indifferent. Some children feel shame and hide the news of their parents' divorce from their friends or pretend it's not happening, other children react by feeling relieved especially if there has been intense fighting in their homes (Clandos \& Kemp, 2007) [2]. General conclusion is that children's reactions to parental divorce depend on each child's personal factors and that even children of the same family may react differently to parental divorce (Zieman \& Baker-Randall (2000) [5].

Factors found to associate with children's reactions to parental divorce include age, gender, socio-economic status, relationship with parents before or after divorce, the degree to which the child was drawn into marital conflict, parents' inability to separate their roles as parent and spouse, continual open conflict between spouses and the perceived loss of the non-custodial parent (Amato \& Keith, 1991 [6]; Hetherington, 1993 [3]; Lachs, (2002) [7]; Kelly \& Emery, 2003 [8]). Amato and Kith (1991) [6] note that gender is associated with children's reactions to parental divorce and that boys are more at risk than girls. Reports by American Academy of Child and

*Address correspondence to this author at the Faculty of Education, University of the Western Cape, Private Bag X17, Bellville 7535 Cape Town, South Africa; E-mail: obojuwoye@uwc.ac.za
Adolescent Psychiatry (2004) [9] and Gruber and Colabella (2008) [10] revealed that immediate problems often found soon after or during marital conflicts and subsequent divorce tend to be more pronounced in boys than girls. Girls tend to internalize problems emanating from divorce while boys tend to externalize them. Boys tend to exhibit more problems later in life than girls. Boys from divorce parents have higher dropout rate from school than girls in the same situation (Brown, 2001) [11]. According to Amato and Keith (1991) [6], there may be no clear cut differences between boys and girls in such areas as academic performance and general psychological adjustment, however, the conclusion arrived at is that the estimated negative effects of divorce on social adjustment are stronger for boys than for girls. One reason given for social adjustment differences between boys and girls is that girls are probably more socially skilled than boys making girls less susceptible to any disruptive effects of parental divorce. However, Amato and Keith (1991) [6] argued that, although increased aggressiveness of boys from divorce families makes their social relationships problematic it cannot be established that boys always suffer more detrimental consequences of divorce than girls.

Age is another important factor found to influence how children perceive and react to parental divorce. Regional Psychosocial Support Initiatives, REPSSI (2007) [12] reports that some cultures may not recognize or expect young children to grieve the loss (through divorce or death) of loved ones. However, Acklin (2008) [13] stated that divorce is painful both to parents and children irrespective of the latter's ages. According to Lachs (2002) [7] parental divorce may not be devastating to older children as with younger children. Amato and Keith (1991) [6] state that younger children are less able to make sense of all the changes that are occurring at the time of divorce. Zieman and Baker-Randall (2000) [5] observed that 
negative effects of divorce are equal for both children of late preschool and middle school. For infants and toddler (due to their immaturity or in-experience) as well as for older adolescents (due to their maturity) these age groups are somewhat protected from the greater effect of the disruption and conflict. Wade and Tavris (1993) [1], however, found that preschool children experience severe distress more than older children, immediately following their parents' divorce. Richardson and Rosen (1999) [14] found some preschool children sad, fearful and suffering serious emotional pain at time of their parents' divorce. Amato and Keith (1991) [6] also found some younger children reacted negatively, feeling confused about their position in relation to non-custodial parent. Preadolescent and adolescent school children, because their close alignment with peers helps them to repress feelings associated with parents' divorce, may not exhibit problems, in short-term (Amato \& Keith 1991) [6]. Zieman and BakerRandall (2000) [5] also note that because of their cognitive maturity adolescents perceive divorce as parents' own problem, than younger children. Usual general reaction of adolescents to parental divorce is to consider institution of marriage as distrustful and unreliable. Tertiary institution students, however, often exhibit behaviour patterns indicating they understand and accept their parents' divorce, without necessarily removing their emotional turmoil. Van Zyl's (1997) [15] conclusion is that divorce, at any age, is a major life event and can be harder for older people just as for younger ones.

While discussing family dynamics which play significant influence on children's reactions to parental divorce, Furstenberg and Kieman (2001) [16] state that divorce does not start with breaking down of marriage. A series of events lead parents to divorce (Leone \& Cole, 2007) [17]. Thus, divorce is culmination of extended process of changing family relationships involving lengthy sequence of pre-divorce experiences (Furstenberg \& Kieman, 2001) [16]. These predivorce experiences are as important as those of divorce itself and children's reactions to parental divorce often depend on family conditions both before and after the divorce. According to Wade \& Tavris (1993) [1] family conditions such as custodial parent's financial status and issues around custody or access are major factors which may elicit different gender reactions to parental divorce. Boys suffer more due to separation from their fathers when mothers have custody. Children who live in custody of same sex parent show significantly more competence, cooperativeness and high self-esteem than those living with opposite sex parent (Wade \& Tavris, 1993) [1]. Pillay (1999) [18] also asserts that absence of same sex parent deprives children of a role model to which they previously had access.

Reactions of children to parental divorce may also be influenced by remarriage of custodial parent. According to Zinsmeister (1996) [19] remarriage of parents can add to, rather than subtract from, the stress of a child. The percentage of children from divorce backgrounds expressing fear of abandonment is higher when mothers remarried than when not. It is further noted that, even where divorce leads children quickly into a solid step-family setting, there tend to be consistent problem. Apart from inability to adjust to step-family situation, remarriage also puts a stop to children's fantasy of possibility of parents reconciling in near future. Another reason for children's negative reaction to remarriage is fear of instability they would experience with the remarriage breaking up again. Wishful comment researchers hear from children of divorced parents is that "if they can get divorce once, they can do it again" (Zinsmeister, 1996) [19].

Pre-divorce conflicts also influence how children react to parental divorce. Lytle (1994) [20] notes the effect of predivorce conflict on children's adjustment to depend on whether or not it serves to prepare children for actual divorce. The assumption is that, in circumstance of intense parental conflict, divorce provides children with a sense of relief since it signifies end to a period of constant animosity between parents. Based on this assumption Mckenry and Price (1994) [21] and Twining (2001) [22] assert that many parents consider option of divorce than to stay in troubled relationships. Divorce is considered far less damaging to children than constant animosity between parents. It is better for children that parents are divorced than to stay together in a very stressful environment of on-going conflicts (Cawood, 2000) [23]. However, Gills (1996) [24] contends that children prefer an unhappy marriage to divorce. Children do not appreciate why parents should not stay married even in an abusive relationship. Pillay (1999) [18] also asserts that children often react to parental divorce with attitudes of disbelief and shock even where there have been series of conflicts at home. Zieman and Baker-Randall (2000) [5] conclude that most often children do not believe there could be irreconcilable differences to warrant parents' divorce.

\section{THE CURRENT STUDY}

According to Prince (2009) [25] an estimated 40\% of South Africa's 18 million children are being raised by single mothers as the nature of the country's traditional family changes. It is further contended that most South African public schools are in dire straits just as the homes, due to growing number of children of divorce. Problems emanating from consequences of divorce have to be fixed. To do this effectively there is need to understand the nature of affected children's problems. Therefore this study was designed with a view to finding out the problems confronting children of divorce from their reported experiences. Specifically the study sought to ascertain the different reactions of participants to parents' divorce and the variables influencing the reactions.

\section{METHODOLOGY}

\section{Participants}

A senior primary school in suburb of Durban, South Africa, was selected for the study. The school's selection was by convenient sampling and based on its having appreciable number of children of divorced parents. The school's choice was further made possible by second researcher's volunteer work in the school. Fifteen children of the school were purposively selected based purely on judgment as to presence of representative or conforming attributes of population intended to be studied (Bless \& Smith, 1995) [26]. Only children with divorce family backgrounds who were capable and willing to relate experiences associated with divorce of parents participated in the study. Parents also had to give consent for their children's participation.

Selection of participants was preceded by a group talk to the school's grades 6, 7, and 8 children. Talk centered on nature of study, roles of participants and beneficial effects of study. Children who initially volunteered to participate in the study were given written form of talk in a letter to their parents. The 
letter was accompanied by a Consent Form for parents to sign to indicate their willingness for their children's participation in the study. Of the more than forty children who initially volunteered to participate, fifteen returned signed consent forms. The fifteen participants comprised six boys and nine girls with ages ranging between 13 and 16 years and a mean age of 14.4 year. All participating children were first language English speakers.

\section{Instrument and Procedure}

Face-to-face individual interview was employed to gather information for the study. The interviews provided opportunity to know and establish rapport with participants and to understand their feelings regarding their parents' divorce. Talking to people is a direct way of getting to know their feelings and experiences (Blanche \& Durrheim, 1999) [27]. Interview provides opportunity for gathering descriptive data in subjects' own words and from perspective of how subjects interpret their worlds (Bodgan \& Taylor, 1999) [28]. Conducting interview, as a natural way of interacting with people to gain qualitative information, is preferred to making people complete a questionnaire, do a test or perform some experimental task (Blanche \& Durrheim, 1999) [27]. Use of interview to investigate children's perspectives on parents' divorce gave the researchers opportunity to look at things, as if, through the eyes of the participants. The interviews were taperecorded and later transcribed for better understanding and interpretation.

\section{Data Analysis}

Content analysis including conceptual and relational analyses, coding and synthesis of data were employed. The interview transcripts were read repeatedly for discovery of recurring themes or patterns in participants' reactions to parental divorce. Themes were developed in accordance with study's aims to ascertain participants' reactions to parents' divorce and family dynamics associated with these reactions.

\section{RESULTS}

Participants described their experiences at time of parents' divorce in different ways. However, recurring theme in reported reactions is that of traumatized experiences at time of parents' divorce. The reported pattern of emotional and behavioural reactions in terms of thoughts and feelings include shock, disbelief, confusion, sadness, anger, loss, betrayal, rejection, abandonment and humiliation. Analysis of interview transcripts also revealed that personal characteristics of participants (age and gender) and family dynamics influenced participants' reactions. The results are presented below according to the recurring themes.

\section{General Pattern of Reactions at time of Parents' Divorce}

Being upset and confused at time of parental divorce were most commonly reported experiences by participants as in excerpts from interview transcripts presented below to indicate how two participants described their feelings:

Its like my whole world is falling apart, as if one part of me is here and the other part is somewhere else

I was very worried and afraid..... I didn't know what was going to happen to me.
Shock and disbelief experiences, as consequence of parental divorce, were also reported as indicated below:

they were happy, so I thought, then they started fighting and decided to get divorce.....I was shocked .....I was very shocked at that time.

Another group of feelings commonly reported are anger, rejection and abandonment. Excerpts below also present participants' descriptions of these traumatic experiences:
I didn't want to talk to either of my parents or anyone after the divorce..... they could have done something to make the marriage work. I blame them for putting us [children] through all the problems we now have......especially my father who left the house.....he walked out on me and even not saying a word to me to indicate he would be coming back.

However not all participants reported negative emotional or behavioural reactions towards their parents' divorce. Some participants reacted rather positively and felt relieved that their parents were finally separated.

A participant reported her feelings that:

I am happier now that they are finally divorced....I rather know that I have a father and a mother who are happier living separately on their own, than staying together and fighting all the time.

Another participant stated that:

I don't feel too badly about my parents' divorce..... I can still see my father as often as I want.

\section{Age and Gender Influences on Children's Reactions to Parents' Divorce}

Analysis of interview transcripts revealed some indications of the influences of age and gender on participants' reactions to patents' divorce. When asked about their feelings at the time of their parents' divorce, the five fifteen-year old participants, whose parents were divorced when they were two or three years old, responded with indifference. They could not remember how they felt at the time of their parents' divorce. For example one participant reported that:

\section{I was very young when my parents got divorced. My mother told me I was about two years old then. It's a long time now and I can't remember anything......... I don't think it has any effect on my school work or my life in general.}

However, not all participants were too young or the time of divorce too long to remember what happened then. Some participants, whose parents divorced about a year or two prior to time of this study's interview, gave graphic details of their experiences which include sobbing bitterly and feeling very sad as they watched their parents fighting one another and as one of them (in most cases fathers) later left in anger and did not return. A fourteen-year old participant, whose parents divorced two years before this study's interview, reported that:

I still care about him [her father] I would have loved to have him around.... I would like to have 
a dad, I miss that, I feel a part of me is gone and it makes me feel sad.

The results of the study seem to suggest that very young children, at time of parents' divorce, are unlikely to understand what is happening in their lives. The results also seem to suggest that when children have grown up, and because parental divorce took place a long time ago, they no longer have memories of the events of that time. However, for children who are in their middle or late teens and their parents have just divorced, the memories of recent events, and probably also their mature age, may make it possible for them to recount the experiences at the time of their parents' divorce. Thus it could be safe to state that age at time of divorce possibly played significant influence in this study's participants' reactions to their parents' divorce.

In terms of influences of gender on children's reactions to parental divorce analysis of interview transcripts revealed that to a very large extent male participants reacted differently in comparison to the reactions of female participants. Generally all participants expressed dissatisfaction with their fathers' absence. Gender differences in reactions seem to relate to how each gender group perceived fathers' role in the family. Almost all male participants reported being unhappy with their parents' divorce because they lost their fathers. The loss of fathers meant they had no same sex parents with who to identify or from who to learn valuable lesions on their gender roles. Excerpt from interview transcripts of a male participant reflects this view as shown below:

\section{It would have been good to have a man around and to have a role model. I feel I'm missing a lot.}

This male participant's response fairly represents other male participants' reactions. A female participant's response to the question regarding loss of her father is that:

I would have loved to have my father around, it would have been nice, because then when my mom is working he can pick me up from school.

Another female participant reported that:

$$
\begin{aligned}
& \text { I feel so bad my mom battles a lot...... She has } \\
& \text { no one to help her and my dad does not support } \\
& \text { us at all. }
\end{aligned}
$$

The reactions of most of the other female participants were in similar manner giving the impression that female participants saw fathers as their mothers' helpers. Male participants saw absence of fathers, or same sex parent, to mean not having a role model, not having a man within the family to identify with or learn from. Female participants interpreted father absence to mean their mothers were being deprived of a helper or somebody who could take up some duties in the home and relieve their mothers of overload. Female participants also interpreted father absence to means not having someone to take up duties women might not be able to do.

\section{Family Dynamics' Influences on Children's Reaction to Parents' Divorce}

Results of data analysis revealed that family dynamics influenced gender differences in children's reactions to parental divorce. Financial status of custodial parent, re-marriage of parents, family relocation and continuing conflict between parents after divorce are some of the family dynamics investigated in this study. Participants' reactions to remarriage of parents were found to depend on gender of children and parents. When asked what their feelings were about their mothers' remarriage, or for those whose mothers were yet to remarry, what their feelings would be if their mothers were to remarry, both male and female participants welcomed their mothers' remarriage. For the boys their step-fathers filled some gaps left by absence of their biological fathers. Having a father figure (even though not biological father), and a father substitute, especially one who could provide financial support and maintain cordial relationship, is all that mattered to most male participants. In this regard a male participant reported that:

\section{I like my step-dad, he sometimes pays my school fees and helps me with my homework, I see him, like a father and I don't mind he is with my mom.}

Another male participant, who acknowledged and valued good interpersonal relationships with his step-father, considered such relationship as a worthy compensation for loss of his biological father by stating that:

\section{I think my step-father is cool he cares about me; I don't mind that he is not my biological father. I like him.}

In reporting favourable feelings toward their mothers' remarriage female participants saw this as having a man in the house to help their mothers especially to provide financial support as reflected in the following female participant's response:

My mom is with another man now. He is also a divorcee and He cares a lot for me, he sometimes pay my school fees. He is good to me, which is reason I don't feel anything, although I miss my real dad.

With regard to non-custodial fathers' remarriage most male participants welcomed this since it did not prevent them from seeing their biological fathers as indicated in a male participant's response:

\section{I am o.k. with my father's remarriage. I can visit him any time. I can talk to him about stuffs, I'm still very close to my dad.}

The results seem to suggest that male participants would welcome remarriage of their absent fathers if the latter maintain cordial relationship with them. Moreover since most male participants of this study expressed favourable relationship with their absent fathers, this could also imply that absentee fathers probably tend to be more concerned about their male offspring than their female offspring.

However, female participants seemed not happy with remarriage of their absentee fathers. They rejected the idea of other women, apart from their mothers, in their fathers' lives. Some female participants resented the idea of another woman taking the place of their mothers as revealed in the following excerpt of interview transcript of a female participant.

My dad has a girlfriend and I don't really care about her, she is not my mom. I don't like my dad's girlfriend at all; I avoid her when I go to see my dad. I hate her, I really feel jealous that someone else is with my dad instead of my mom. 
A major family dynamic, which seemed to greatly evoked participants' strong affect response has to do with custodial parents' economic status. Poor financial status of custodial parents seemed to have negatively impacted on participants' adjustment to parents' divorce. Many participants reported being very adversely affected by financial hardships their custodial parents were going through. One participant responded that she felt ....so bad because my mom battles a lot with money, she has no helper and my dad does not support us at all.

Another participant stated that:

my mom does not work...., she is medically boarded. The divorce has really affected us financially.

Even in cases where participants were supported to go to school, poor economic status of custodial parents often mean poor quality education as a participant reported that:

\section{Ifeel the divorce has affected my studies because if my dad were around he would contribute and then I would go to a better school and have all fancy stuffs like other kids....Even my stuffs cost a lot of money and my mom battles sometimes, I feel a little bit unhappy.}

However, where a custodial parent is able to provide adequate financial support or where non-custodial parents provided financial support and or maintained cordial relationship with children, and barring all other pressures, participants seemed to report better adjustment to parental divorce. Three participants of this study reported being adequately provided for by their custodial parents and that their non-custodial parents (absentee fathers) also provided financial support. They reported that they were not seriously affected any negatively than they would have because of their parents' divorce or subsequent absence of their fathers. One of the participants' response reflected the feelings of other two participants when he stated that:

\section{I don't feel too badly about my parents' divorce, I can see my dad anytime. My dad takes me out often, he pays for my school fees and everything.... and he gives me all I need, even gifts sometime.}

Results of data analysis revealed one specific way poor financial status of custodial parent affected children's adjustment post-divorce. This is with regard to changes in living arrangements. Relocation or residential moves destroy children's sense of normalcy. Dramatic losses in incomes by custodial parents often meant instability in normal life as the family may have to relocate or move residence to more affordable housing. This usually means adjustments to new communities and loss of ties with former neighbours. The implications of unstable lifestyle resulting from residential moves include diminished ability to concentrate, plan or to even have a goal to pursue in form of future career as reflected in a participant's response that:

moving here and there has affected my school works because I'm always going different places and sometimes it is hard for me to concentrate on anything, because it might change tomorrow.
Some participants also reported custody arrangements as major contributor to instability and poor adjustment postdivorce. Two participants reported being in joint custody arrangements and had to move from one parent home to another especially on weekends. Reflecting feelings of the two participants, a participant described his experience that:

I have to be changing places quite often because my dad likes to change houses and still expects me to follow him everywhere in order to spend time with him too. This instability is really affecting me and I feel very unhappy about the divorce.

However, relocation did not seem to influence participants' adjustment, post-divorce, as much as continued conflicts between parents even after divorce. Finance which was responsible for relocation by families and hence instability in family life was also at the heart of constant conflicts and bitterness between parents as they argued over maintenance. This had negative psychological impact on affected participants. In this connection two excerpts from interview transcripts of participants' reported reactions are presented below:

My dad cannot visit me, he doesn't see eye-to-eye with my mother. He doesn't like my mother. They don't talk at all and it breaks my heart. The only thing that can make me feel better is if my mother and father could at least be friends, even if they cannot be married again, but at least be friends. I am going through a lot of pain right now, I can't even concentrate on my school work.

Even now that my parents are divorced they still fight on the phone over maintenance. They shout and yell at each other. It is affecting me and I wish they could just stop fighting.

\section{DISCUSSION}

This was a case study which employed interview for data collection from rather very small sample size. Although the results cannot be generalized, however, the findings certainly provide some insights into the nature of problems children of divorce may be going through as can be garnered from participants' reaction patterns and family dynamics influencing the reactions at time of parental divorce. It is noteworthy that some findings of this study seem to be consistent with previous study findings. For instance, those of Wallerstein and Blakeslee (2003) [29]; Ellis (2000) [30] and Samenow (2002) [31] who also found that divorce could be very traumatic for children. Since home is the whole world of children, when this home becomes unsafe due to parental divorce children can be expected to react rather very negatively either emotionally and or behaviorally (Samenow, 2002) [31]. Divorce makes children unsafe, uncertain of the future or makes children feel that the future is bleak and they become helpless because they fear that something bad could happen to them (Wallerstein \& Blakeslee (2003) [29].

The results of the study also revealed gender differences in children's reactions to parental divorce. This could be because of the differential perceptions of the role of fathers in the family by the boys and girls. This result is consistent with McLanahan's (2008) [32] finding and notes further that the consequences of growing up without a father are more 
pronounced for boys than for girls because boys are more dependent on a male role model. Chen (2008) [33] also notes that because fathers meant different things to boys and girls in terms of the different attitudes and values they acquire from their fathers this may be responsible for the gender differences in the perceptions of fathers in the family. Fathers influence boys' gender role behaviour development. Boys learn from their fathers about male interests, activities, social behaviour or generally about growing up as a male. Chen (2008) [33] also notes that girls too learn from their fathers to develop trusting comfortable relationship with men.

However, perhaps a more important finding of this study is the role of family economic condition or the custodial parent's financial status on post-divorce adjustment of children. The results of this study revealed that, not only did poor financial status of custodial parent affected the children, it determined the effects of other family dynamics on post-divorce adjustment of the children. Poor financial status of custodial parents was found to have greatly influenced how children perceived parental divorce and how they perceived the role or absence of their fathers. Poor financial status greatly influenced the normalcy of children's daily routine or the stability of children's lives, children's social relationship and children's efforts to plan and build towards the future. Poor economic status of custodial parent exerted very powerful negative impacts on almost all aspects of the children's life and well-being. It is also noteworthy that poor financial status of custodial parents could be implicated in the gender differences regarding children's perceptions of divorce, perceptions of father's role in the family and acceptance or rejection of parents' remarriage.

According to MacLanahan (2008) [32] households headed by divorced mothers have significantly fewer financial resources and reduced access to all the advantages money can buy. Without fathers' incomes the consequences for household finances is dire. Implications of low incomes of households headed by divorced mothers may include children not being supported financially for proper nourishment, for payment of school fees, for transportation to school, for provision of learning support materials and even for parental emotional support and encouragement for children to go to school and or remain in school (Zimmerman \& Thayer, 2003 [34]; Kirby \& Dean, 2004) [35]). Poor academic performance, conduct problems and dropout from school completely are also attributed to poor financial status of custodial parents (Acklin, 2008) [13]. Dramatic losses in incomes by divorced mothers result in disrupted life or life stresses for children (Kirby \& Dean, 2004) [35] as financial difficulties could mean decreased parental care and protection, reduced parental affection or emotional and material supports and generally children's lack of satisfaction with parenting role. Further implication of custodial parent's economic hardships could also be that schools filled with significantly high number of children from divorce backgrounds may have to grabble with children whose sense of normalcy have been destroyed, who are depressed or have low self-esteem and poor self-efficacy. It can also be expected that such schools would have problems of underachievement, disregard for authorities of teachers and other adults, sexual acting out, drug abuse and generally with children who are physically, psychologically or emotionally traumatized.

Since the homes have been rendered dysfunctional, due to divorce, the implication is that schools have the added responsibilities of being only structures of support for children in the throes of their growth and development. Unfortunately all recommendations on how to cushion the negative impacts of divorce on children, as contained in the literature are directed to homes. Specific suggestions as to courses of action to take to assist children's adjustment to parental divorce are directed to parents. However, children belong to both home and school worlds. Divorce is contributing significantly to changes in nature of traditional family with an estimated $40 \%$ of South Africa's 18 million children being raised by single mothers (Prince, 2009) [25]. This means that the main support structure for children's growth and development, the homes, are continuously being rendered less capable of their responsibilities. Families as nucleus of the society are less and less capable of passing down values which shape the society (Prince, 2009) [25]. There must be a place for children to turn to when parents are emotionally and physically unavailable to give their children support and affection and to teach them what they need to know, or to help them when they have problems. Schools, therefore, are the next logical places for children to turn to and be rescued from confusion and mixed emotions experienced as consequence of divorce. Children have right to lead normal life, to have good quality of life and to reach their potential. The National Education Policy Act, 1996 (South Africa Department of Education, 1996) [36] stipulates that teachers should take up much wider role than it has been traditionally including being caregivers, mentors, pastors, leaders in the community and other roles. This stipulation should not just be within the context of HIV/AIDS but also from the perspective of the fact that the homes, and hence the parents, can no long play their traditional roles due to divorce. Schools should care and support children according to their specific needs and on the basis of their ages and genders. The implication of age and gender differences found with regard to children's reactions to parents' divorce are indications of different needs and problems of children depending on their age and gender and depending on the dynamics of their families. These added responsibilities of schools have implications for teacher preparation programmes since teachers must be equipped with necessary skills and the right attitudes to care for and support children in schools. Teachers have to be equipped with skills not just for providing academic support but also for physical, social and emotional care and support. Increasing number of children traumatized by parents' divorce will also need specialist attention and this means that schools will need to be supplied with specialist support services providers including school counselors or school psychologists. The intention here is not to suggest that schools take over completely home responsibilities to children. However, the greatest responsibility of re-establishing order in homes, made dysfunctional due to divorce, rest with schools. Schools, therefore, need to be equipped with personnel with appropriate skills, attitudes and values for designing, identifying and implementing appropriate programmes to empower homes to promote and maintain the health and overall well-being of children.

\section{CONCLUSION}

According to Prince (2009) [25] seven million children are growing up with single mothers outnumbering the 6.2 million - 
about 34\% of South Africa's children - who live with both parents. The phenomenon of single parent households is largely being contributed to by divorce. With increasing divorce rate and increasing number of children growing up in broken and dysfunctional homes, the risk of breeding dysfunctional society seems very apparent. While the results of this study confirmed previous study findings that divorce is traumatic to children physically, socially and emotionally, the study findings also further emphasize consequence of divorce for children and especially with schools being presented with children burdened by problems depending on their age and gender as well as on their family dynamics. Since dysfunctional homes are unlikely to effectively help children to develop and live normal life, schools have to take up additional responsibilities of homes in children's development. Confronted with array of children from divorce backgrounds and with different needs, teachers' role has to widen to include provision of various other forms of support and care apart from academic.

\section{REFERENCES}

[1] Wade C, Tavris C. Psychology. New York: Collins Publishers 1993.

[2] Clandos R, Kemp G. Children and separation/divorce: helping your child cope [Online]. 2007 August 4 [cited 2007]. Available from: http://www.helpguide.org/mental/children divorce.htm

[3] Hetherington EM. An overview of the Virginia longitudinal study of divorce and remarriage with a focus on the early adolescent. J Fam Psychol 1993; 7: 39-56.

[4] Amato PR. Lifespan adjustment of children to their parents' divorce. Future Child 1994; 4: 143-16.

[5] Zieman G, Baker-Randall MA. Children's reactions to divorce: shortterm and long-term effects. Parenting New Mexico, Part 1, in a series on Dealing with Divorce 2000.

[6] Amato PR, Keith B. Parental divorce and the well-being of children: a meta-analysis. Psychol Bull 1991; 110: 26-46.

[7] Lachs MS. Divorce: help with the aftermath. Prevention 2002; 54(12): 3 .

[8] Kelly JB, Emery RE. Children's adjustment following divorce: risk and resiliency perspectives. Fam Relat 2003; 52: 352-62.

[9] American academy of child and adolescent psychiatry. Facts for families: children and divorce. [Online]. 2004 August 6. [cited 2009] Available from: http://www.aacap.org.ww?section=Facts+for+Famili es\&name $=$ Children + And $=$ Div

[10] Gruber, Colabella PA. What about the kids? - The best interest's standard. [Online]. 2008 April 3 [cited 2009]. Available from: http://www.divorcesource.com/NJ/ARTICLES/gruber2.htm1

[11] Brown K. How divorce affects adolescents. [Online]. 2001 June 20 [cited 2009]. Available from: http://www.inside.bard.edu/academic/ specialproj/darling/aadfmb2.htm

[12] Regional Psychosocial Support Initiatives (REPSSI). Psychological wellbeing series: psychosocial care and support for children and infants in the time of HIV and AIDS. Randburg, Johannesburg, South Africa: REPSSI Organization Creative Commons 2007.
[13] Acklin MW. Divorce your spouse not the kids. [Online]. 2008 April 3. [cited 2009], Available from: http//:www.divorcesource.com/HI/ARTI CLES/acklin2.html

[14] Richardson CD, Rosen LA. School-based intervention for children of divorce. Prof Sch Couns 1999; 3(1): 21-8.

[15] van Zyl L. Divorce mediation and the best interests of the child. Pretoria, South Africa: Human Sciences Research Council 1997.

[16] Furstenberg FF, Kieman KE. Delayed parental divorce: how much do children benefit? J Marriage Fam 2001; 63 (2): 446.

[17] Leon K, Cole K. Helping children understand divorce. [Online]. 2007 August 6. [cited 2009]. Available from: http://www.extension.missouri. edu/xplor/hesguide/humanrel/gh6600.htm

[18] Pillay S. An investigative study if the process of divorce and its effects on children. Masters [dissertation]. Durban: University of Kwazulu Natal 1999

[19] Zinsmeister K. Divorce toll on children. Am Enterp 1996; 17 (3): 39.

[20] Lytle V. Information about health factors that affect the way students learn. California: NEA Today 1994.

[21] McKenry PC, Price SJ. Families and change: coping with stressful events. London: International Educational and Professional Publisher 1994.

[22] Twining K. Success in Psychology. New York: Murray Publishers 2001.

[23] Cawood A. Why children with problems tend to misbehave. Cape Town, South Africa: Juta \& Co. 2000.

[24] Gills H. Counselling young people. Pretoria, South Africa: Kagiso Publishers 1996.

[25] Prince C. The changing face of the South African family: single moms now the norm. South Africa: Sunday Times newspaper 2009; 22; 9 .

[26] Bless C, Smith H. Fundamentals of social research. Cape Town, South Africa: Juta \& Co. 1995.

[27] Blanche MT, Durrheim K. Research in practice: applied method for the social sciences. Cape Town: University of Cape Town Press 1999.

[28] Bogdan R, Taylor SJ. Introduction to qualitative research method: a guidebook and resource. Chischester: John Willey 1999.

[29] Wallerstein JS, Blakeslee S. What about the kids. New York: Hyperion 2003.

[30] Ellis E. Divorce wars: intervention with families in conflict. Baltimore: Port City Press 2000.

[31] Samenow SE. In the best interest of the child: how to protect your child from pain of divorce. New York: Crown Publishers 2002.

[32] McLanahan S. Father absence and the welfare of children. [Online]. 2008 February 27 [cited 2009]. Available from: http://www.olin. wustl.edu/macarthur/working\%20papers/wp-mclanahan2.htm

[33] Chen, N. The impact of father absence. [Online]. 2008 February 27. [cited 2009]. Available from: http://extension.missouri.edu/cooper/fok/ father_absence.htm

[34] Zimmerman J. Thayer ES. Adult children of divorce: how to overcome the legacy of your parents' breakup and enjoy love, trust and intimacy. Oakland, California: New Harbiner Publications Inc. 2003.

[35] Kirby JJ, Dean K. Teens and divorce: what hurts and what helps? [Online]. 2004 August 4. [cited 2009]. Available from: http://ohioline.osu.edu/flm02FS11.htm1

[36] South Africa. Department of Education. National Policy on HIV/AIDS for learners in public schools (National Education Policy Act No. 27). Pretoria, South Africa: Government Printers 1996.

(C) Bojuwoye and Akpan; Licensee Bentham Open.

This is an open access article licensed under the terms of the Creative Commons Attribution Non-Commercial License (http://creativecommons.org/licenses/by-nc/3.0/) which permits unrestricted, non-commercial use, distribution and reproduction in any medium, provided the work is properly cited. 